Imalat Teknolojileri ve Uygulamalar

Cilt: 2, No: 2, 2021 (1-9)

Araştırma Makalesi

e-ISSN: 2717-7475
Manufacturing Technologies and Applications

Vol: 2, Issue: 2, 2021 (1-9)

Research Article

e-ISSN: $2717-7475$

\title{
AISI P20S Kalıp Çeliğinin İşlenebilirliğinin İncelenmesi
}

\author{
Mücahit Coşkun ${ }^{1, *}$ (D), İbrahim Çiftçi ${ }^{2}$, Halil Demir ${ }^{3}$ (D) \\ ${ }^{I}$ Ondokuz Mayıs Üniversitesi, Yeşilyurt Demir Çelik Meslek Yüksekokulu, Samsun, Türkiye \\ ${ }^{2}$ Çankırı Karatekin Üniversitesi, Mühendislik Fakültesi, Çankırı, Türkiye \\ ${ }^{3}$ Karabük Üniversitesi, Türkiye Odalar ve Borsalar Birliği Teknik Bilimler Meslek Yüksekokulu, Karabük, Türkiye
}

\section{MAKALE BILGISII}

Alınma: 08.03.2021

Kabul: 26.07.2021

Anahtar Kelimeler:

İslenebilirlik

Kalıp çeliği

Frezeleme

Kesme kuvveti

Yüzey pürüzlülüğ̈̈

\section{ÖZET}

Bu çalışmada, kalıpçılık sektöründe yaygın olarak kullanılan AISI P20S kalıp çeliği tercih edilmiştir. Farklı kesme parmetreleri (kesme hızı, ilerleme miktarı ve kesme derinliği) kullanılarak gerçekleştirilen deneylerde değişkenlerin kesme kuvveti ve yüzey pürüzlülüğü üzerine etkileri incelenmiştir. Kaplamalı karbür kesici takım kullanılarak frezeleme yöntemi ile gerçekleştirilen bu deneylerde işleme parametreleri olarak kesme hızı ve ilerme miktarının dört farklı değișkeni, kesme derinliğinin ise iki farklı değişkeni kullanılmıştır. Elde edilen sonuçlar değerlendirildiğinde artan kesme hızına bağlı olarak kesme kuvveti değerlerinde azalma meydana gelirken ilerleme miktarının artan değerlerinde ise kesme kuvveti değerlerinde artış tespit edilmiştir. En yüksek kesme kuvveti $(138.1 \mathrm{~N}) 170 \mathrm{~m} /$ dak kesme hızı, $0.253 \mathrm{~mm} /$ diş ilerleme ve 1.5 mm kesme derinliğinde ölçülürken, en düşük kesme kuvveti değeri $(45.23 \mathrm{~N})$ ise 0.75 $\mathrm{mm}$ talaş derinliğinde, $260 \mathrm{~m} /$ dak kesme hızı, $0.075 \mathrm{~mm} /$ diş ilerlemede ölçülmüştür. Ayrıca artan kesme hızı değerleri yüzey pürüzlülüğünün azalmasına, artan ilerleme miktarı ve kesme derinliği değerlerinin ise yüzey pürüzlülüğünün artmasına neden olduğu görülmüştür. En düşük yüzey pürüzlülüğü $(0.273 \mu \mathrm{m}) 260 \mathrm{~m} /$ dak kesme hızı, $0.075 \mathrm{~mm} /$ diş ilerleme hızında ve $0.75 \mathrm{~mm}$ kesme derinliğinde ölçülürken, en yüksek yüzey pürüzlülük değeri $(1.552 \mu \mathrm{m})$ ise $170 \mathrm{~m} /$ dak kesme hızı, $0.253 \mathrm{~mm} /$ diş ilerleme miktarı ve $1.5 \mathrm{~mm}$ kesme derinliğinde oluşmuştur. Sonuç olarak yüksek kesme hızı, düşük ilerleme miktarı ve kesme derinliği değerlerinin en iyi işleme çıktılarının elde edilmesinde etkili olduğunu söylemek mümkündür.

\section{Investigation of Machinability of AISI P20S Mold Steel}

\section{ARTICLE INFO}

Received: 08.03.2021

Accepted: 26.07 .2021

Keywords:

Machinability

Mold steel

Milling

Cutting force

Surface roughness

\section{ABSTRACT}

In this study, AISI P20S mold steel, which is widely used in the mold making industry, was preferred. The effects of the variables on the cutting force and surface roughness were investigated in the experiments performed using different cutting parameters (cutting speed, feed rate and depth of cut). In these experiments, which were carried out with the milling method using a coated carbide cutting tool, four different variables of cutting speed and feed rate and two different variables of cutting depth were used as machining parameters. When the obtained results are evaluated, it is determined that while the cutting force values decrease depending on the increasing cutting speed, an increase in the cutting force values is observed at the increasing values of the feed amount. The highest cutting force $(138.1 \mathrm{~N})$ is measured at 170 $\mathrm{m} / \mathrm{min}$ cutting speed, $0.253 \mathrm{~mm} /$ tooth feed and $1.5 \mathrm{~mm}$ depth of cut, while the lowest cutting force $(45.23 \mathrm{~N})$ is measured at $0.75 \mathrm{~mm}$ depth of cut, measured at $260 \mathrm{~m} / \mathrm{min}$ cutting speed, $0.075 \mathrm{~mm} /$ tooth feed. In addition, it was observed that increasing cutting speed values caused a decrease in surface roughness, while increasing feed rate and cutting depth values caused an increase in surface roughness. The lowest surface roughness $(0.273 \mu \mathrm{m})$ was measured at $260 \mathrm{~m} / \mathrm{min}$ cutting speed, 0.075 $\mathrm{mm} /$ tooth feed rate and $0.75 \mathrm{~mm}$ depth of cut, while the highest surface roughness value $(1.552 \mu \mathrm{m})$ was measured at $170 \mathrm{~m} / \mathrm{min}$ cutting speed, $0.253 \mathrm{~mm} /$ tooth feed rate and $1.5 \mathrm{~mm}$ depth of cut. As a result, it is possible to say that high cutting speed, low feed rate and depth of cut values are effective in obtaining the best machining outputs.

\footnotetext{
* Sorumlu yazar, e-posta: mucahit.coskun@omu.edu.tr 


\section{GİRIŞ (INTRODUCTION)}

Gelişen teknolojiyle endüstriyel sektör de gelişmiştir. Bununla beraber yapılacak veya üretilecek her ürün için birçok talaşılı imalat yöntemi bulunmaktadır. Talaşlı üretim yöntemlerinden biri frezeleme yöntemidir ve bu yöntem endüstride önemli bir yer kaplamaktadır. Frezeleme yöntemi, makine, uzay, havacılık, otomotiv ve makine imalatlarında yaygın olarak kullanılmaktadır. $\mathrm{Bu}$ yöntem ile düzlemsel, eğik, dairesel parçalar ve karmaşıklı̆̆ı fazla olmayan parçalar işlenebilmektedir. Frezeleme işleminde kullanılan kesici takımlarda birden fazla kesici kenar bulunmasından dolayı elde edilen ürünün yüzey kalitesi oldukça iyi elde edilebilmektedir. Ayrıca üretilmek istenen ürünün ölçüleri çok dar toleranslar dahilinde üretilebilmektedir [1].

Talaşlı üretimde tezgâhın, kesici takımın ve işleme yönteminin yanı sıra işleme parametreleri de önemlidir. Bu parametreler, kesme hızı, kesme derinliği ve ilerleme miktarıdır. Bu parametreler iş parçasında yüzey kalitesini etkilemektedir. Ayrıca oluşan kesme kuvveti ile takım ömrünü belirlemektedir. $\mathrm{Bu}$ nedenle talaşlı üretime başlamadan önce işleme parametrelerinin iyi belirlenmesi gerekmektedir [2].

Kalıp imalatında, iş parçası malzemesinin seçimi önemli bir yer kaplamaktadır. Seçimi yapılacak çeliğin yalnızca mekanik özellikleri değil kimyasal özellikleri ve işlenebilirliği dikkate alınmalıdır [3]. Ayrıca kalıbın kullanım yerine ve boyutsal ölçülerine göre de ikincil bir işlem gerekebilmektedir. Bu ikincil işlem genellikle ısıl işlem olmaktadır. Fakat ısıl işlem sırasında çelikte çatlama gibi deformasyonlar meydana gelebilmektedir. Dolayısıyla seçilecek kalıp çeliğinin ısıl işleme gerek duyulmadan kullanılabilir olması avantajlı bir durum olmaktadır. Ön sertleştirme işlemi ile üretilen AISI P20S çeliğinin 30-35 HRC sertlikte olduğu, ölçü tamlığının ve işlenebilirliğinin kolay olduğu belirtilmektedir.

$\mathrm{Bu}$ çalışmada; talaşlı imalatta kullanılan plastik kalıp çeliklerinin işleme sonrası 1sıl işleme gönderilmesine gerek duyulmayan, sertleştirilmiş halde üretilmiş AISI P20S çeliğinden talaş kaldırılması için ihtiyaç duyulan işleme parametrelerinin incelenmesi amaçlanmıştır.

\section{MATERYAL VE YÖNTEM (MATERIAL AND METHOD)}

\section{1. İş Parçası ve Takım Özellikleri (Workpiece and Tool Properties)}

$\mathrm{Bu}$ çalışmada iş parçası malzemesi olarak AISI P20S çeliği kullanılmıştır. İçeriğinde bulundurduğu kükürt (S) elementi nedeniyle yüksek yüzey parlaklığ 1 beklenmeyen orta ve büyük hacimli plastik enjeksiyon kalıpları, destek plakaları, basınçlı döküm ve plastik enjeksiyon kalıpları için kalıp kasaları, kauçuk türü plastik ürünlerin baskı kalıpları, ekstrüzyon preslerinin kovanları, otomotiv ve gıda endüstrisi için plastik kalıpları ve yüksek sıvı basıncı altında metallerin şekillendirme kalıplarında kullanılmaktadır [3]. AISI P20S kalıp çeliğinin kimyasal bileşimi Tablo 1'de, mekanik özellikleri ise Tablo 2'de verilmiştir [4]. İş parçası malzemesinin boyutları Şekil 1'de gösterilmiştir.
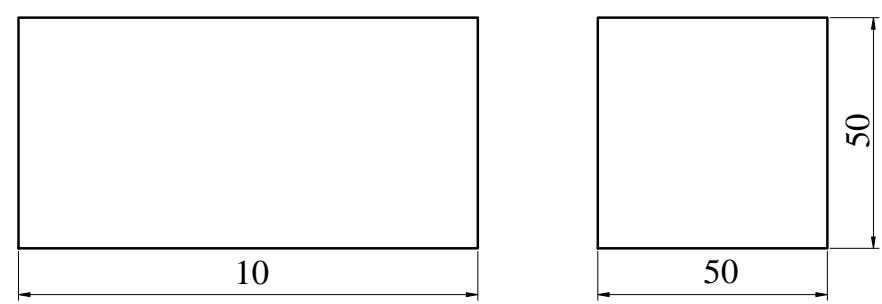

Şekil 1. İş parçası malzemesi boyutları (Workpiece material dimensions)

Tablo 1. AISI P20S kalıp çeliğinin kimyasal bileşimi (Chemical composition of AISI P20S mold steel)

\begin{tabular}{cccccccc}
\hline $\mathbf{C}$ & $\mathbf{S i}$ & $\mathbf{N i}$ & $\mathbf{M n}$ & $\mathbf{C r}$ & $\mathbf{M o}$ & $\mathbf{S}$ & $\mathbf{P}$ \\
\hline $0.35-0.45$ & $0.20-0.40$ & $0.30-0.50$ & $1.30-1.60$ & $1.80-2.10$ & $0.15-0.25$ & $0.05-0.10$ & Max 0.30 \\
\hline
\end{tabular}


Tablo 2. AISI P20S kalıp çeliğinin mekanik özellikleri (Mechanical properties of AISI P20S mold steel)

\begin{tabular}{cccc}
\hline $\begin{array}{c}\text { Yoğunluk } \\
\left(\mathrm{g} / \mathrm{cm}^{3}\right)\end{array}$ & $\begin{array}{c}\text { Isıl İletkenlik } \\
(\mathrm{W} / \mathrm{m} \cdot \mathrm{K})\end{array}$ & $\begin{array}{c}\text { Elastikiyet Modülü } \\
(\mathrm{GPa})\end{array}$ & $\begin{array}{c}\text { Akma Dayanımı } \\
(\mathrm{MPa})\end{array}$ \\
\hline 7.83 & 34.0 & 210 & 880 \\
\hline
\end{tabular}

İşleme deneylerinde Mitsubishi firması tarafindan üretilen PVD yöntemiyle kaplama işlemi gerçekleştirilmiş AOMT123608PEER-M kodlu karbür kesici takım kullanılmıştır. Kullanılan kesici takımın özellikleri Tablo 3'te verilmiştir.

Tablo 3. Kesici takım geometrisi ve özellikleri (Cutting tool geometry and properties)

\begin{tabular}{ccccccc}
\hline $\begin{array}{c}\text { Takım } \\
\text { Geometrisi }\end{array}$ & Takım Kodu & $\begin{array}{c}\text { Takım } \\
\text { Malzemesi }\end{array}$ & Kaplama & Kalite & $\begin{array}{c}\text { Takım Tutucu } \\
\text { Çapı }\end{array}$ & $\begin{array}{c}\text { Diş } \\
\text { Sayısı }\end{array}$ \\
\hline AOMT123608PEER-M & $\begin{array}{c}\text { Sementit } \\
\text { karbür }\end{array}$ & $\begin{array}{c}\text { MIRACLE } \\
\text { TiAlN }\end{array}$ & P20 & $16 \mathrm{~mm}$ & 1 adet \\
\hline
\end{tabular}

\subsection{Takım Tezgâhı Özellikleri (Machine Tool Properties)}

Deneylerde kullanılan iş parçaları FANUC kontrol ünitesine sahip Johnford VMC-550 CNC dik işlem merkezinde kesme sıvısı kullanılmadan işlenmiştir. Deney düzeneğinin şematik gösterimi Şekil 2'de ve kullanılan CNC dik işlem merkezinin özellikleri Tablo 4'te verilmiştir.

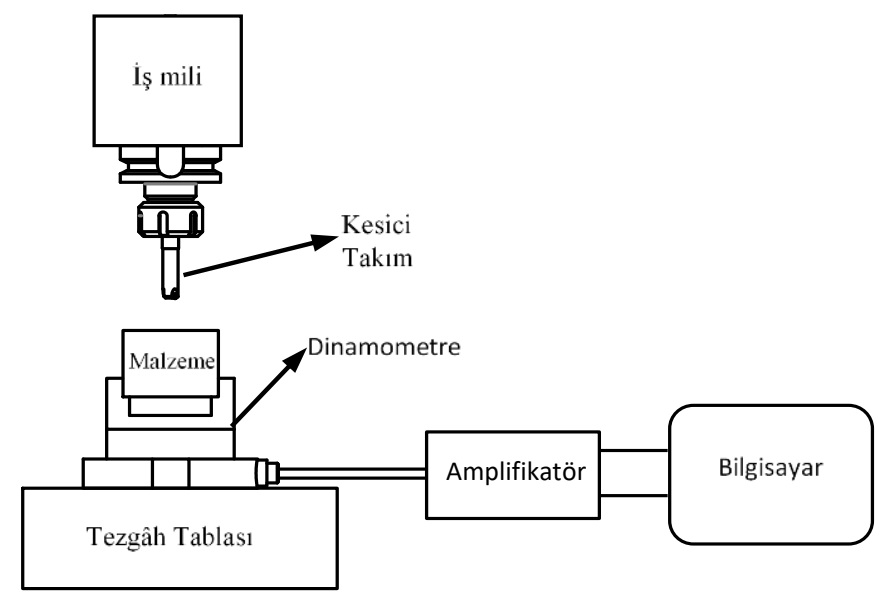

Şekil 2. Deney düzeneğinin şematik gösterimi (Schematic representation of the experimental setup)

Tablo 4. CNC freze tezgâhının özellikleri (Features of CNC milling machine)

\begin{tabular}{ll}
\hline Model & Johnford VMC-550 Dik İşlem Merkezi \\
\hline Kontrol tipi & Fanuc O-M serisi \\
\hline $\mathbf{X}, \mathbf{Y}, \mathbf{Z}$ ekseni hareketi & $500 \times 500 \times 450 \mathrm{~mm}$ \\
\hline Hassasiyeti & $0,001 \mathrm{~mm}$ \\
\hline Devir sayısı (En yüksek) & $6000 \mathrm{dev} / \mathrm{dak}$ \\
\hline Motor gücü & $10 \mathrm{HP}(7.5 \mathrm{~kW})$ \\
\hline X-Y-Z hızlı ilerleme & $15-15-12 \mathrm{~m} / \mathrm{dak}$ \\
\hline Kesme ilerlemesi & $1-4000 \mathrm{~mm} / \mathrm{dak}$ \\
\hline
\end{tabular}

\subsection{Kesme Kuvvetlerinin Ölçülmesi (Measurement of Cutting Forces)}

Talaş kaldırma esnasında oluşan kuvvetler KİSTLER 9257B tipi dinamometre ile ölçülmüştür (Şekil 3). Ölçülecek kuvvet, bir üst plaka vasıtasıyla tanımlanır ve taban ve üst plaka arasına yerleştirilen dört adet üç bileşenli kuvvet sensörü arasında dağıtılır. Bu dört kuvvet sensöründe tanımlanan kuvvet üç bileşene ayrılır. 3 bileşendeki kuvvet ölçümü için, bağımsız sinyaller bağlantı kablosunda bir araya getirilir. 6 bileşenli kuvvet ve moment ölçümü için, 8 ayrı sinyalin tümü 
bağlantı kablosu vasıtasıyla şarj amplifikatörlerine doğrudan gönderilir [5]. Amplifikatöre gelen sinyaller bilgisayara aktarılır.

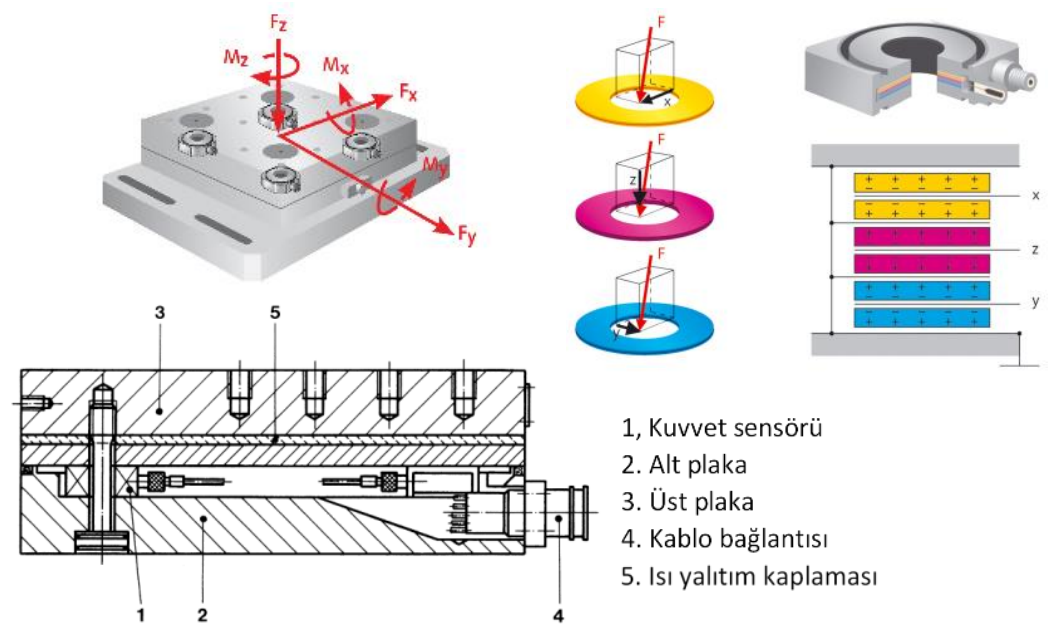

Şekil 3. Kistler 9257B dinamometresinin elemanlar1 [30] (Elements of the Kistler 9257B dynamometer)

Bilgisayara aktarılan veriler Dynoware yazılımı ile incelenmiştir. Dynoware yazılımı kesme kuvvetlerinin bilgisayar yardımı ile ölçülmesini sağlayan bir programdır. Bilgisayara aktarılan verilerin Dynoware yazılımı ile görüntülenmesi Şekil 4'te verilmiştir.

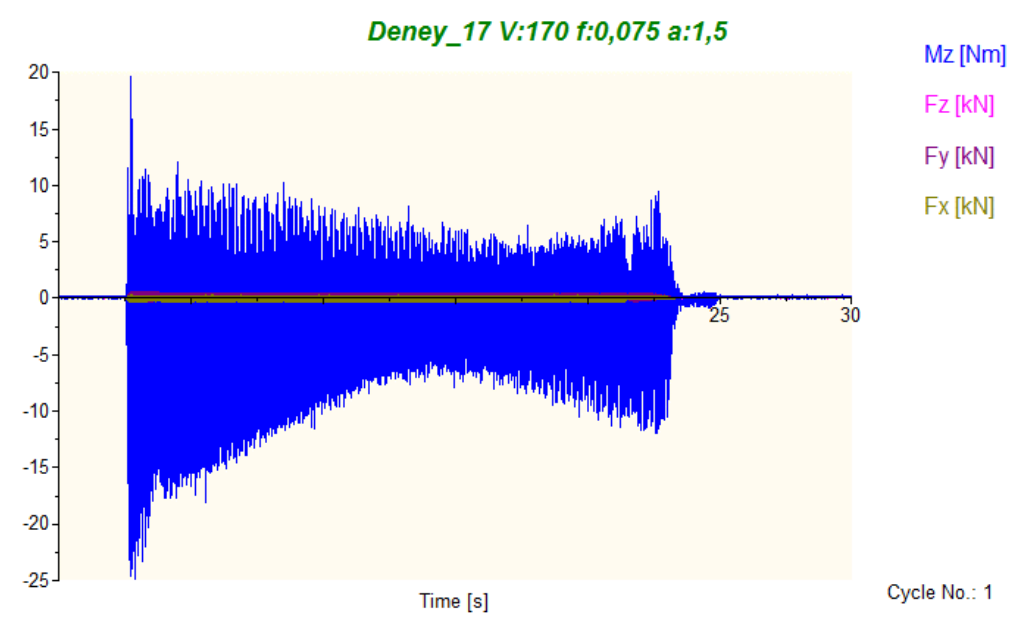

Şekil 4. Kesme kuvvetlerinin Dynoware yazılımı ile görüntülenmesi (Display of cutting forces with Dynoware software)

Kesme işlemi esnasında dinamometre üzerinde oluşan kuvvetlerin ölçülebilmesi için gereken süre işleme deneylerinin her biri için 30 saniye olarak ayarlanmıştır. Kesme kuvveti değerleri talaş kaldırma işlemi esnasında 3 eksende ölçülmüştür. Elde edilen kesme kuvveti değerleri Dynoware yazılımında görüntülenerek kuvvetlerin kararlı olduğu bölgenin başlangıç ve bitiş konumları esas alınıp bu bölgedeki değerlerin ortalamaları alınarak Fx, Fy ve Fz kuvvetleri belirlenmiştir.

\subsection{Yüzey Pürüzlülüğünün Ölçümü (Measurement of Surface Roughness)}

İşlenmiş yüzeyler üzerinde yüzey pürüzlülüğü ölçümleri için Marsurf PS1 yüzey pürüzlülük ölçüm cihazı kullanılmıştır. Pürüzlülük ölçümleri için örnekleme uzunluğu $4 \mathrm{~mm}$ ve ölçüm uzunluğu $0.8 \mathrm{~mm}$ olarak alınmıştır. Kullanılan pürüzlülük ölçüm cihazının özellikleri Tablo 5'te verilmiştir. Yüzey pürüzlülüğü olarak ortalama yüzey pürüzlülük (Ra) değeri dikkate alınmıştır.

\subsection{Deneysel Parametreler (Experimental Parameters)}

Deneysel çalışmalar iki farklı kesme derinliği, dört farklı kesme hızı ve dört farklı ilerleme miktarı kullanılarak karbür kesici takımlar ile gerçekleştirilmiştir. İşleme parametreleri Tablo 6'da verilmiştir. 
Tablo 5. Pürüzlülük ölçüm cihazının özellikleri (Features of the roughness measuring device)

\begin{tabular}{ll}
\hline Model & Mahr (Marsurf PS1) \\
\hline Ölçüm yöntemi & İzleyici uçlu cihazlar yöntemi \\
\hline Tarama hızı & $0.5 \mathrm{~mm} / \mathrm{sn}$ (ölçüm yaparken) \\
& $1 \mathrm{~mm} / \mathrm{sn}$ (geri dönüşte) \\
\hline Ölçme Kuvveti & $4 \mathrm{mN}(0.4 \mathrm{gf})$ \\
\hline Uç malzemesi & Elmas \\
\hline Ölçme sıcaklığı & $20^{\circ} \mathrm{C} \pm 1{ }^{\circ} \mathrm{C}$ \\
\hline Numune uzunluğu & $0.8 \mathrm{~mm}$ \\
\hline Değerlendirme uzunluğu & $4 \mathrm{~mm}$ \\
\hline İzleyici uç yarıçapı & $5 \mu \mathrm{m}$ \\
\hline
\end{tabular}

Tablo 6. Deney değişkenleri (Experiment variables)

\begin{tabular}{ll}
\hline İş parçası malzemesi & AISI P20S \\
\hline Kesme hızı (V) & $170,200,230,260 \mathrm{~m} /$ dak \\
\hline İlerleme (f) & $0.075 ; 0.113 ; 0.169 ; 0.253 \mathrm{~mm} /$ diş \\
\hline Eksenel kesme derinliği & $0.75 ; 1.5 \mathrm{~mm}$ \\
\hline Radyal kesme genişliği & $8 \mathrm{~mm}$ \\
\hline Kesme boyu & $100 \mathrm{~mm}$ \\
\hline
\end{tabular}

\section{DENEY SONUÇLARININ DEĞERLENDİRILMESİ (EVOLUATION OF EXPERIMENT RESULTS)}

\subsection{Kesme Kuvvetleri (Cutting Forces)}

Deneysel çalışmalar esnasında meydana gelen kesme kuvveti değerleri aynı anda üç düzlemde kuvvet ölçme kabiliyetine sahip bir dinamometre ile ölçülmüştür. Kesme kuvveti ölçümlerinde her bir parametre için yeni kesici takım kullanılmış olup toplamda otuz iki deney gerçekleştirilmiştir. Deneylerde ilerleme yönü freze tezgâhının Y ekseni boyunca tek yönde verilmiş olduğundan, en büyük kuvvetler Y ekseninde gözlenmiştir. Bu nedenle değerlendirmelerde kesme kuvveti olarak Fy bileşenleri dikkate alınmıştır. Deneyler sırasında meydana gelen kesme kuvveti grafikleri Şekil 5'de verilmiştir.
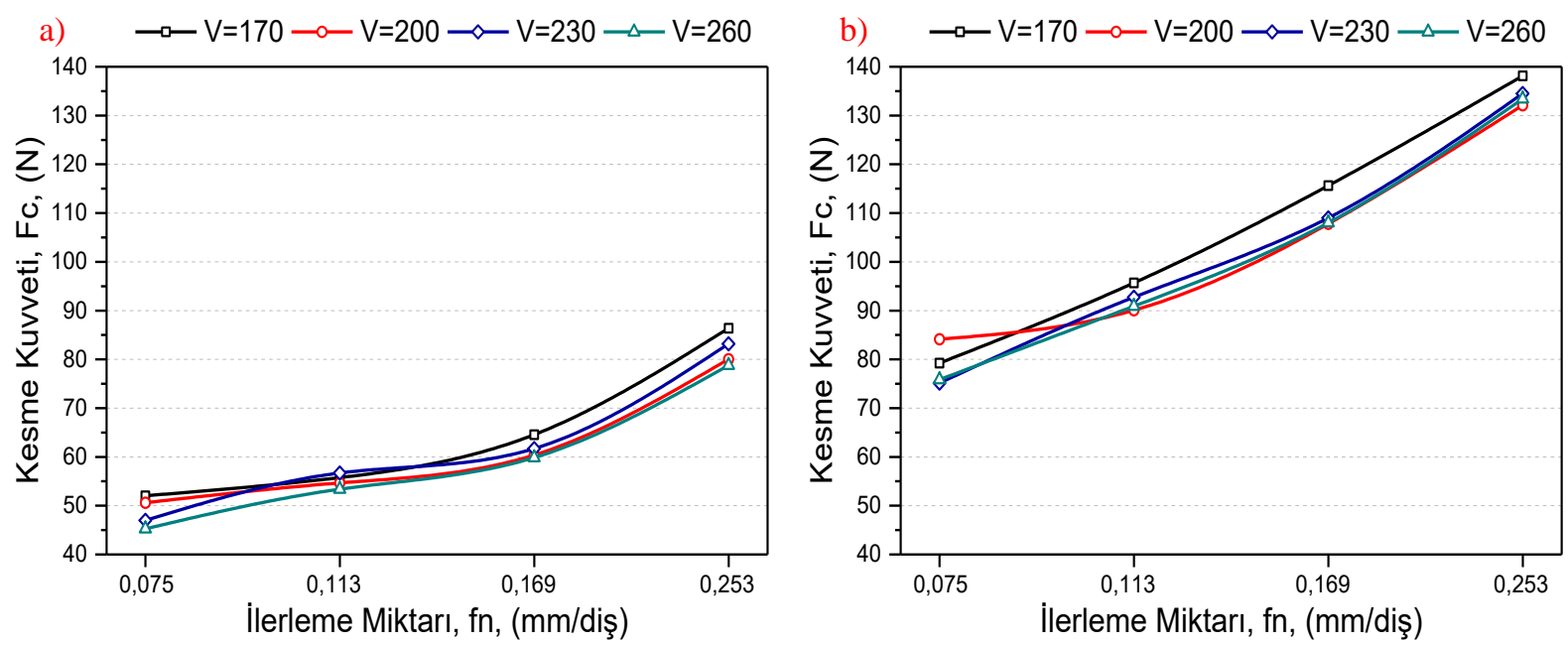

Şekil 5. İlerleme miktarı ve kesme hızının kesme kuvvetine etkisi (Effect of feed rate and cutting speed on cuting force) a) $0.75 \mathrm{~mm}$ kesme derinliği b) $1.5 \mathrm{~mm}$ kesme derinliği

0,75 mm kesme derinliğinde ilerleme miktarlarının artmasıyla kesme kuvvetlerinin arttığı Şekil 5a'da görülmektedir. Kesme kuvvetlerideki bu artışın sebebi talaş kesitinin artmasına atfedilebilir 
[6]. İlerleme miktarı arttıkça talaş kesiti artar ve bu da kesme kuvvetlerinin artmasına sebeb olur. Meydana gelen en yüksek kesme kuvveti değeri $(86.36 \mathrm{~N})$ ilerleme miktarının $0.253 \mathrm{~mm} /$ diş, kesme hızının $170 \mathrm{~m} /$ dak parametrelerinde oluşmuştur. En düşük kesme kuvveti değeri $(45.23 \mathrm{~N})$ ise 0.075 $\mathrm{mm} /$ diş ilerleme miktarı, $260 \mathrm{~m} /$ dak kesme hızında oluşmuştur. İlerleme miktarının 0.075 $\mathrm{mm} /$ diş’ten $0.113 \mathrm{~mm}$ /diş'e artışında kesme kuvveti değerleri 3.7 ile $9.7 \mathrm{~N}$ arasında değişirken ilerleme miktarlarının $0.113 \mathrm{~mm} /$ diş’ten sonra $0.169 \mathrm{~mm} /$ diş ve $0.253 \mathrm{~mm} /$ diş'e arttırılması ile kesme kuvvetlerinde $5 \mathrm{~N}$ ile $21.8 \mathrm{~N}$ arasında değişimler meydana gelmiştir. Kesme kuvvetlerinde meydana gelen en fazla değişim \%34.86 ile ilerleme miktarının $0.169 \mathrm{~mm} /$ diş’ten $0.253 \mathrm{~mm} /$ diş'e artışında $230 \mathrm{~m} /$ dak kesme hızında gözlenmiştir. En düşük değişim \%7.21 olarak ilerleme miktarının $0.075 \mathrm{~mm} /$ diş’ten $0.113 \mathrm{~mm}$ /diş'e artışında $170 \mathrm{~m} /$ dak kesme hızında meydana gelmiştir. En düşük kesme kuvveti değeri ile en yüksek kesme kuvveti değeri arasında yaklaşık olarak \%90.93'lük bir değişim meydana gelmiştir.

Şekil 5b'deki grafik incelendiğinde $1.5 \mathrm{~mm}$ kesme derinliğinde ilerleme miktarlarının artmasıyla kesme kuvvetlerinin de arttığ 1 görülmektedir. Meydana gelen en yüksek kesme kuvveti değeri $(138.1 \mathrm{~N})$ ilerleme miktarının $0.253 \mathrm{~mm} /$ diş, kesme hızının $170 \mathrm{~m} /$ dak oduğu durumda oluşmuştur. En düşük kesme kuvveti değeri $(75.1 \mathrm{~N})$ ise $0.075 \mathrm{~mm} /$ diş ilerleme miktarı, $230 \mathrm{~m} /$ dak kesme hızında oluşmuştur. İlerleme miktarının $0.075 \mathrm{~mm} /$ diş’ten $0.113 \mathrm{~mm} /$ diş'e artışında kesme kuvveti değerleri $6 \mathrm{~N}$ ile $17.6 \mathrm{~N}$ arasında değişirken ilerleme miktarlarının $0.113 \mathrm{~mm} /$ diş’ten sonra 0.169 $\mathrm{mm} /$ diş ve $0.253 \mathrm{~mm} /$ diş'e arttırılması ile kesme kuvvetlerinde 16.2 ile $25.5 \mathrm{~N}$ arasında değişimler meydana gelmiştir. Kesme kuvvetlerinde meydana gelen en fazla değişim \%23.51 ile ilerleme miktarının $0.169 \mathrm{~mm} /$ diş’ten $0.253 \mathrm{~mm} /$ diş'e artışında $260 \mathrm{~m} /$ dak kesme hızında gözlenmiştir. En düşük değişim \%7.07 olarak ilerleme miktarının $0.075 \mathrm{~mm} /$ diş’ten $0.113 \mathrm{~mm} /$ diş’e artışında 200 m/dak kesme hızında meydana gelmiştir. En düşük kesme kuvveti değeri ile en yüksek kesme kuvveti değeri arasında yaklaşık olarak \%83.88'lik bir değişim meydana gelmiştir.

Şekil 5'deki grafikler kıyaslandığında kesme derinliğinin 0.5 mm'den 1. mm'ye çıkarılmasıyla, iş parçası malzemesinden talaş kaldırmak için gereken kuvvet değerlerinde artış meydana geldiği görülmektedir. $\mathrm{Bu}$ durum kesme derinliğinin artmasıyla kesici takımın iş parçası yüzeyinden kaldırdığı talaş miktarının artmasından dolayı, talaş kaldırma işlemi için daha fazla kuvvet gerektirmesinden kaynaklanmaktadır [6].

Kesme hızı ve ilerleme miktarının kesme kuvveti üzerine etkileri Şekil 6'da verilmiştir.
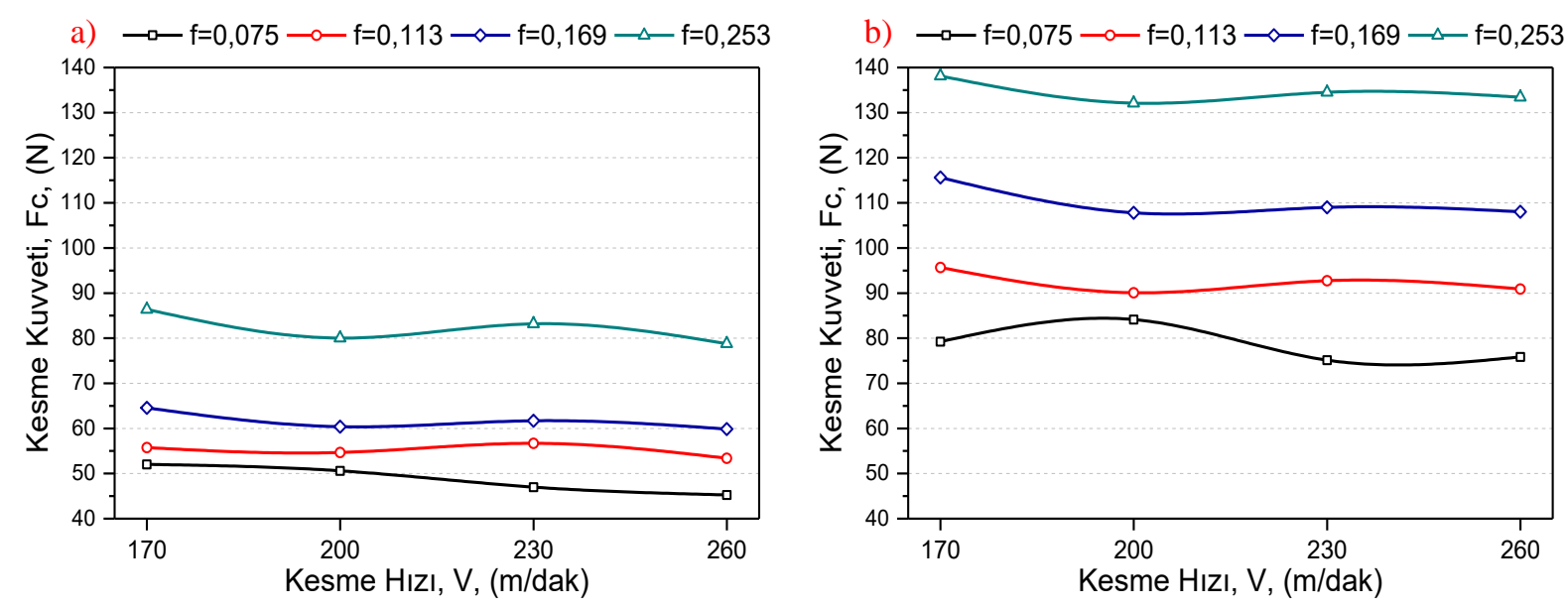

Şekil 6. Kesme hızı ve ilerleme miktarının kesme kuvvetine etkisi (Effect of cutting speed and feed rate on cuting force) a) $0.75 \mathrm{~mm}$ kesme derinliği b) $1.5 \mathrm{~mm}$ kesme derinliği

Şekil 6a'daki grafik incelendiğinde $0.75 \mathrm{~mm}$ kesme derinliğinde kesme hızının artmasıyla kesme kuvvetlerinde düşüş meydana geldiği görülmektedir. Kesme hızının artmasıyla kesme kuvvetlerinde meydana gelen düşüş takım talaş arayüzeyinde temas alanının azalmasıyla ve artan kesme hızıyla meydana gelen sıcaklığın artması sonucu takım talaş arayüzeyine yapışan malzemenin kayma dayanımının düşmesiyle açıklanabilir [7-9]. Kesme hızının 170 m/dak'dan 200 m/dak'ya artışında kesme kuvveti değerleri $1 \mathrm{~N}$ ile $6 \mathrm{~N}$ arasında değişirken, kesme hızının $200 \mathrm{~m} /$ dak'dan $230 \mathrm{~m} /$ dak 
ve $260 \mathrm{~m} /$ dak'ya arttırılması ile kesme kuvvetlerinde $1.2 \mathrm{~N}$ ile $4.4 \mathrm{~N}$ arasında değişimler meydana gelmiştir. Kesme kuvvetlerinde meydana gelen en fazla değişim \%7.36 ile kesme hızının 170 $\mathrm{m} /$ dak'dan $200 \mathrm{~m} /$ dak'ya artışında $0.253 \mathrm{~mm} /$ diş ilerleme miktarında meydana gelirken, en düşük değişim ise yaklaşık \%1.95 olarak kesme hızının $170 \mathrm{~m} /$ dak'dan $200 \mathrm{~m} /$ dak'ya artışında 0.113 $\mathrm{mm}$ /diş ilerleme miktarında meydana gelmiştir.

Şekil 6b'deki grafik incelendiğinde $1.5 \mathrm{~mm}$ kesme derinliğinde kesme hızının artmasıyla kesme kuvvetlerinde düşüş meydana geldiği görülmektedir. $200 \mathrm{~m} /$ dak kesme hızında ve ilerleme miktarının $0.075 \mathrm{~mm} /$ diş olarak yapılan deneylerde bir önceki kesme hızı değerine $(170 \mathrm{~m} / \mathrm{dak})$ göre kesme kuvvetinde yaklaşık olarak \%6.17 artış meydana geldiği görülmektedir. Bunun sebebi olarak düşük ve orta hızlarda kesme işlemi gerçekleştirirken meydana gelen yığıntı talaş oluşumunun kesici uç geometrisini değiştirerek kesme işlemi için gereken kuvveti arttırdığından dolayı kaynaklandığını söyleyebiliriz [10]. Kesme hızının 170 m/dak'dan 200 m/dak'ya artışında kesme kuvveti değerleri $4.8 \mathrm{~N}$ ile $7.8 \mathrm{~N}$ arasında değişirken kesme hızının $200 \mathrm{~m} /$ dak'dan 230 $\mathrm{m} /$ dak ve $260 \mathrm{~m} /$ dak'ya arttırılması ile kesme kuvvetlerinde $1 \mathrm{~N}$ ile $9 \mathrm{~N}$ arasında değişimler meydana gelmiştir. Kesme kuvvetlerinde meydana gelen en fazla değişim \%10.71 ile kesme hızının $200 \mathrm{~m} /$ dak' dan $230 \mathrm{~m} /$ dak'ya artışında $0.075 \mathrm{~mm} /$ diş ilerleme miktarında meydana gelirken, en düşük değişim ise yaklaşık \%0.81 olarak kesme hızının $230 \mathrm{~m} /$ dak'dan $260 \mathrm{~m} /$ dak'ya artışında $0.253 \mathrm{~mm} /$ diş ilerleme miktarında meydana gelmiştir.

\subsection{Yüzey Pürüzlülüğü (Surface Roughness)}

Şekil 7'deki grafiklerden anlaşılabileceği gibi kesme derinliğinin $0.75 \mathrm{~mm}$ den $1.5 \mathrm{~mm}$ ye çıkarılmasıyla iş parçası malzemesinin işlenen yüzeyinde oluşan pürüzlülük değerlerinde ciddi bir şekilde artış meydana geldiği görülmektedir. Kesme derinliğinin artması kesici takımın iş parçasının yüzeyinden kaldırdığı talaş miktarını arttıracağından, kesici takımda oluşan titreşimlerin artmasına neden olmaktadır. Kesici takımda oluşan titreşimlerin artması, işparçasının yüzey pürüzlülügünün artmasına neden olmaktadır.
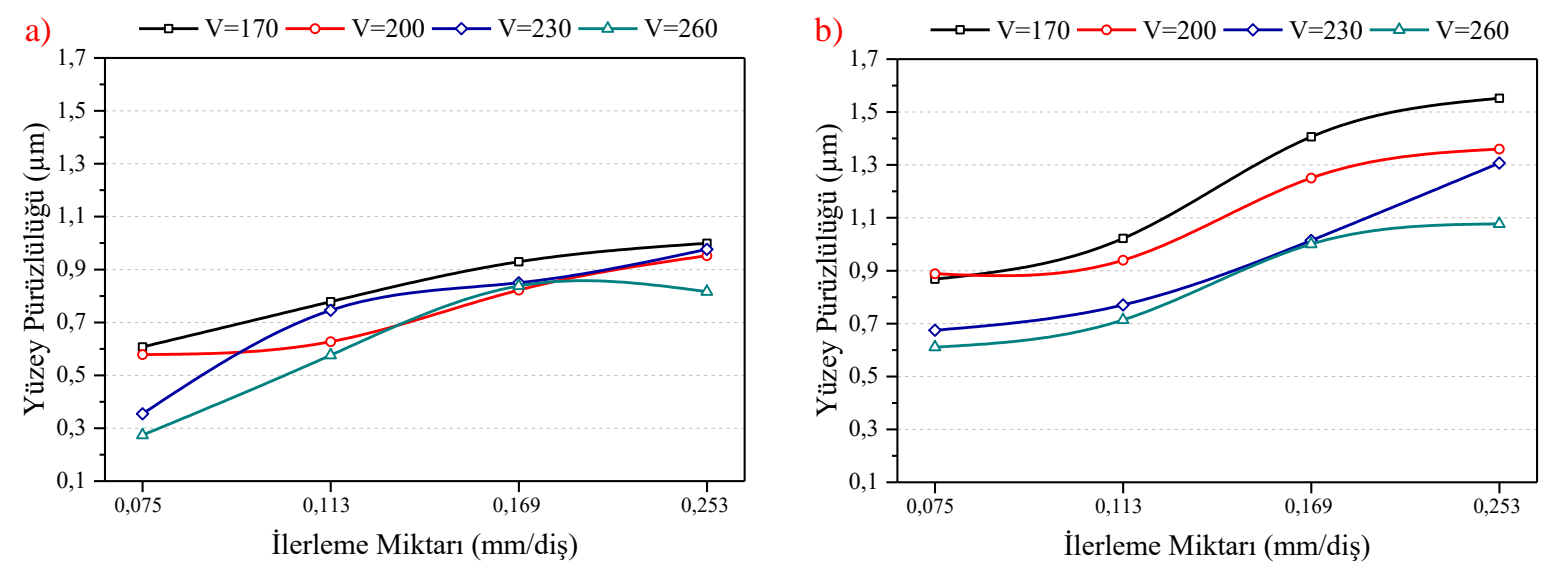

Şekil 7. İlerleme miktarı ve kesme hızına bağlı ortalama yüzey pürüzlülüğü değerleri (Average surface roughness values depending on the feed rate and cutting speed) a) $0.75 \mathrm{~mm}$ kesme derinliği b) $1.5 \mathrm{~mm}$ kesme derinliği

Şekil 7a'daki grafik incelendiğinde ilerleme miktarının artması ile yüzey pürüzlülüğünün arttığı görülmektedir. İlerleme miktarının artması kesici takımın iş parçası yüzeyinden kaldıracağı talaş hacminin artmasına neden olacağından dolayı kesici takımda oluşan titreşimleri arttırmaktadır, bu nedenle ilerleme miktarının artması işlenen yüzeyin pürüzlülüğünü arttırmaktadır [11-15]. Grafikteki verilere göre meydana gelen en yüksek yüzey pürüzlülüğü $(0.999 \mu \mathrm{m}) 0.253 \mathrm{~mm} / \mathrm{diş}$ ilerleme miktarında ve $170 \mathrm{~m} /$ dak kesme hızında oluşmuştur. En düşük yüzey pürüzlülüğü $(0.273$ $\mu \mathrm{m}$ ) değeri ise $0.075 \mathrm{~mm} /$ diş ilerleme miktarında ve $260 \mathrm{~m} /$ dak kesme hızında meydana gelmiştir.

Şekil 7b'deki grafiğin genel olarak incelenmesi ile ilerleme miktarındaki artışın yüzey pürüzlülük değerlerini de artırdığı görülmektedir. Grafikteki verilere göre meydana gelen en yüksek yüzey pürüzlülüğü $(1.552 \mu \mathrm{m}) 0.253 \mathrm{~mm} /$ diş ilerleme miktarında ve $170 \mathrm{~m} /$ dak kesme hızında 
oluşmuştur. En düşük yüzey pürüzlülüğü değeri $(0.611 \mu \mathrm{m})$ ise $0.075 \mathrm{~mm} /$ diş ilerleme miktarında ve $260 \mathrm{~m} /$ dak kesme hızında meydana gelmiştir.

Şekil 7a ve Şekil 7b'deki grafiklerden de anlaşılabileceği gibi kesme hızına bağlı olarak yüzey pürüzlülük değerleri incelendiğinde, kesme hızının artmasıyla yüzey pürüzlülüğünün düştüğü görülmektedir. Artan kesme hızıyla yüzey pürüzlülüğünün düşmesinin nedeni azalan BUE eğilimi olarak gösterilebilir [16,17]. BUE kesici takımın ucunda oluşarak işlenen yüzeyin pürüzlülük değerinin artmasına neden olmaktadır. Kesme hızının artması BUE oluşma eğilimini azaltır ve bu durum da yüzey pürüzlülük değerinin azalmasına neden olur.

\section{SONUÇLAR (CONCLUSIONS)}

AISI P20S plastik kalıp çeliğinin Sementit karbür kesici takımlar ile kuru kesme şartlarında işlenmesi esnasında işleme parametrelerinin kesme kuvvetleri ve işleme sonrası meydana gelen yüzey pürüzlülük değerlerinin üzerindeki etkileri deneysel çalışmalar yapılarak incelenmiştir. Çalışma boyunca 32 adet deney yapılmış ve elde edilen deneysel veriler değerlendirildiğinde aşağıdaki sonuçlar söylenebilir;

- İlerleme miktarının artması ile kesme kuvvetlerinde ve yüzey pürüzlülüklerinde artış meydana gelmiştir. Bu artış yapılan deneylerin literatür ile paralel olduğunu göstermiştir.

- Kesme hızının artması ile işleme esnasında meydana gelen kesme kuvvetleri ve yüzey pürüzlülük değerleri azalmıştır.

- $\quad$ Artan kesme derinliği, kesme kuvveti ve yüzey pürüzlülük değerlerini arttırmıştır.

- $\quad$ En yüksek kesme kuvveti değeri $(138.1 \mathrm{~N}) 1.5 \mathrm{~mm}$ kesme derinliğinde, kesme hızının 170 $\mathrm{m} /$ dak, ilerleme miktarının $0.253 \mathrm{~mm} /$ diş olduğu parametrede meydana gelmiştir. En düşük kesme kuvveti değeri $(45.23 \mathrm{~N})$ ise $0.75 \mathrm{~mm}$ kesme derinliğinde, kesme hızının $260 \mathrm{~m} /$ dak, ilerleme miktarının $0,075 \mathrm{~mm} /$ diş olduğu parametrede meydana gelmiştir.

- $\quad$ En yüksek yüzey pürüzlülük değeri $(1.552 \mu \mathrm{m}) 1.5 \mathrm{~mm}$ kesme derinliğinde, kesme hızının $170 \mathrm{~m} /$ dak, ilerleme miktarının $0.253 \mathrm{~mm} /$ diş olduğu durumda meydana gelmiştir. En düşük pürüzlülük değeri $(0.273 \mu \mathrm{m})$ ise $0.75 \mathrm{~mm}$ kesme derinliğinde, kesme hızının $260 \mathrm{~m} / \mathrm{dak}$, ilerleme miktarının $0.075 \mathrm{~mm} /$ diş olduğu durumda meydana gelmiştir.

\section{TEŞEKKÜR (ACKNOWLEDGMENT)}

Bu çalışma Karabük Üniversitesi Bilimsel Araştırma Projeleri tarafından desteklenmiştir (Proje no: KBÜ-BAP 15/2-YL-046).

\section{KAYNAKLAR (REFERENCES)}

1. A. Gezgin, Prizmatik parçaların frezelenmesi esnasında kesici uç sayısının takım ömrü ve yüzey pürüzlülüğü açısından değerlendirilmesi, Yüksek Lisans Tezi, Gazi Üniversitesi Fen Bilimleri Enstitüsü, Ankara, Türkiye, 2007.

2. M.C. Çakır, Modern Talaşlı İmalatın Esasları, Nobel Yayın Dağıtımı, Ankara, 50-80, 2006.

3. M. Süngünyol, Y. Kayır, DIN 1.2311 ve 1.2738 Kalıp Çeliklerinin İşlenebilirliği, 3. Ulusal Talaşlı İmalat Sempozyumu, 4-5 Ekim 2012, Ankara.

4. Korkmaz Çelik, Plastik Kalıp Çelikleri, http://www.korkmazcelik.com/urunler/plastik-kalipcelikleri.html, 20.11.2017.

5. Kistler, Measure Analize Innovate, https://www.kistler.com/en/product/type-9257b/, 15.10.2017.

6. İ. Korkut, M.A. Dönertaş, Kesme parametrelerinin frezelemede oluşan kesme kuvvetleri üzerindeki etkileri, Gazi Üniversitesi Politeknik Dergisi, 6(1): 385-389, 2003.

7. İ. Çiftçi, Talaşlı İmalatta Yüzey Pürüzlülügünün Tayini Ders Notları, Karabük Üniversitesi Teknik Eğitim Fakültesi, Karabük, 2004.

8. Sandvik Coromant, Modern Metal Cutting, Practical Handbook, Sandvik, Sweden, 1994.

9. M.C. Shaw, Metal Cutting Principles, Oxford University Press, London, 1984.

10. B. Haddag, S. Atlati, M. Nouari, A. Moufki, Dry machining aeronautical aluminum alloy AA2024T351: Analysis of cutting forces, chip segmentation and built-up edge formation, Metals, 6(9), 197, 2016. 
11. K. Bouacha, M.A. Yallese, T. Mabrouki, J.F. Rigal, Statistical analysis of surface roughness and cutting forces using response surface methodology in hard turning of AISI 52100 bearing steel with CBN tool, International Journal of Refractory Metals and Hard Materials, 28(3), 349-361, 2010.

12. D.S. Kilic, S. Raman, Observations of the tool-chip boundary conditions in turning of aluminum alloys, Wear, 262(7-8), 889-904, 2007.

13. R. Suresh, S. Basavarajappa, V.N. Gaitonde, G.L. Samuel, Machinability investigations on hardened AISI 4340 steel using coated carbide insert, International Journal of Refractory Metals and Hard Materials, 33, 75-86, 2012.

14. A. Pal, S.K. Choudhury, S. Chinchanikar, Machinability assessment through experimental investigation during hard and soft turning of hardened steel, Procedia Materials Science, 6, 80- 91, 2014.

15. B. Özlü, H. Demir, M. Türkmen, and S. Gündüz, The Investigation of Surface Roughness and Cutting Forces of Steels Cooled in Sand and Air After Hot Forging, Technological Applied Science, 14(1). 2030, 2019.

16. İ. Çiftçi, Machining of austenitic stainless steels using CVD multi-layer coated cemented carbide tools, Tribology International, 39, 103-109, 2006.

17. S. Thamizhmanii, K. Kamarudin, E.A. Rahim, A. Saparudin, S. Hassan, Tool Wear and Surface Roughness in Turning AISI 8620 Using Coated Ceramic Tool, Proceedings of the World Congress on Engineering, 2-4 July 2007, London. 